\title{
PENGARUH KEPEMIMPINAN KEPALA SEKOLAH, BUDAYA SEKOLAH, IKLIM ORGANISASI, DAN MANAJEMEN MUTU GURU TERHADAP HASIL BELAJAR SISWA SMKN DI D. I. YOGYAKARTA
}

\author{
Indah Wahyuni ${ }^{1}$, Darmono ${ }^{2}$, Husaini Usman ${ }^{3}$ \\ 1,2,3 Pendidikan Teknik Sipil dan Perencanaan, FT, UNY \\ Email: indahwahyuni@uny.ac.id
}

\begin{abstract}
ABSTRAK
Tujuan kajian ini adalah untuk mengetahui sejauh mana pengaruh kepemimpinan kepala sekolah terhadap prestasi belajar siswa SMKN di Provinsi D.I. Yogyakarta melalui 5 tinjauan variabel bebas, yaitu: "Kepemimpinan Kepala Sekolah (X1), Budaya Sekolah (X2), Iklim Organisasi (X3), Manajemen Mutu Guru (X4), dan Total Quality Management (X5)”. Kelima variabel bebas tersebut akan dilihat sejauhmana besar pengaruhnya terhadap Prestasi Belajar Siswa (Y) yang merupakan variabel terikat dalam kajian ini. Jenis kajian ini termasuk penelitian kuantitatif dengan menggunakan desain penelitian korelasional. Populasi dalam kajian ini adalah 69 orang di SMKN di Provinsi D.I Yogyakarta dan sample yang diambil sebanyak 61 guru. Analisis data menggunakan dua teknik yaitu statistik deskriptif kuantitatif dan yang kedua menggunakan Regresi. Melalui 61 responden didapatkan hasil bahwa Hasil Belajar Siswa (Y) sangat dipengaruhi oleh Kepemimpinan Kepala Sekolah (X1), Budaya Sekolah (X2), Iklim Organisasi (X3), Manajemen Mutu Guru (X4), dan Total Quaity Managemen (X5).
\end{abstract}

Kata Kunci: budaya sekolah, hasil belajar, kepemimpinan Kepala Sekolah, manajemen mutu,

\begin{abstract}
The study aims to determine the extent of the influence of school principal leadership on student achievement in SMKN in the Province of D.I. Yogyakarta through 5 reviews of independent variables, namely: "Principal Leadership (X1), School Culture (X2), Organizational Climate (X3), Teacher Quality Management (X4), and Total Quality Management (X5)". The five independent variables will be seen to what extent their influence on Student Learning Achievement $(Y)$ which is the dependent variable in this study. This type of study includes quantitative research using a correlational research design. The population in this study was 69 people at SMKN in Yogyakarta D.I Province and the sample taken was 61 teachers. Data analysis uses two techniques namely quantitative descriptive statistics and the second uses Regression. Through 61 respondents the results show that Student Learning Outcomes (Y) are strongly influenced by Principal Leadership (X1), School Culture (X2), Organizational Climate (X3), Teacher Quality Management (X4), and Total Quaity Management (X5).
\end{abstract}

Keyword: School Culture, Learning outcomes, school principal leadership, Total Quality Management

\section{PENDAHULUAN}

Pada dasarnya setiap manusia adalah pemimpin, minimal memimpin dirinya sendiri. Makna kepemimpinan dapat dirumuskan sebagai berikut "kepemimpinan adalah kemampuan dan kesiapan yang dimiliki oleh seseorang untuk dapat mempengaruhi, mendorong, mengajak menuntut, menggerakkan mengarahkan dan kalau perlu memaksa orang atau kelompok agar menerima pengaruh tersebut dan selanjutnya berbuat sesuatu yang dapat 
membantu tercapainya suatu tujuan tertentu yang telah ditetapkan".

Para ahli kepemimpinan pendidikan dan beberapa hasil penelitian membuktikan bahwa sukses atau gagalnya sekolah ditentukan oleh kepemimpinan kepala sekolahnya (Lunenberg \& Orstein, 2002 \& Hoy \& Miskel, 2013). Kepala sekolah adalah seorang fungsional guru yang diberi tugas untuk memimpin suatu sekolah dimana diselenggarakan proses belajar mengajar, atau tempat dimana terjadi interaksi antara guru yang memberi pelajaran dengan murid yang menerima pelajaran.

Berdasarkan data Education For All (EFA) Global Monitoring Report 2011: The Hidden Crisis, Armed Conflict and Education yang dikeluarkan Unesco menunjukkan bahwa Indeks Pembangunan Pendidikan (Education Development Index disingkat EDI) Indonesia tahun 2008 adalah 0,934. Walaupun laporan dari lembaga dunia namun belumlah cukup peningkatan tersebut dijadikan pegangan bahwa SDM Indonesia sudah dapat dikatakan mempunyai keunggulan di peraturan dunia. Sebelumnya pada tanggal 14 Maret 2013 UNDP juga melaporkan tentang Human Development Index (HDI) yang menyatakan bahwa posisi Indonesia pada tahun 2012 berada di peringkat 121 dari 187 negara. Ranking tersebut masih tertinggal jauh dari posisi beberapa negara di Asean lainnya, seperti: Malaysia (64), Brunai Darusalam (30), dan yang berada pada peringkat teratas yaitu Singapura (18). Data ini menunjukkan bahwa output mutu pendidikan di Indonesia masih belum dapat berkontribusi banyak terhadap pengembangan sumberdaya manusia dan selalu tertinggal di lingkungan NegaraNegara Asean.
Indikator berikutnya yaitu berdasarkan hasil analisis dari Badan Akreditasi Nasional Sekolah/Madrasah (BAN S/M), disebutkan bahwa untuk periode akreditasi tahun 2008-2012, capaian nilai akreditasi S/M belum baik. Persentasi S/M untuk tingkat pendidikan dasar dan menengah yang memperoleh nilai A masih rendah, yaitu untuk tingkat $\mathrm{SD} / \mathrm{MI}=15,2 \%$; SMP/MTs $=28,5 \%$; SMA/MA=32,5\%; dan SMK/MAK=41\% (Abdul Mukti, 2013: 6).

Makna dari hasil analisis BAN S/M tersebut menunjukkan bahwa untuk tingkat SD/MI sebesar 84,8\%; SMP/MTs sebesar 71,5\%; SMA/MA sebesar 67,5\%; dan SMK/MAK sebesar 59\% kondisi S/M mutunya masih di bawah 8 Standar Nasional Pendidikan (8 SNP) atau secara garis besar dapat dikatakan bahwa mutu S/M lebih dari 50\% masih di bawah 8 Standar Nasional Pendidikan (SNP).

Indek tersebut menempatkan Indonesia diposisi ke-69 dari 127 negara didunia. Mutu pendidikan Indonesia berada dibawah negara-negara Asean. Rendahnya mutu pendidikan memprihatinkan dunia pendidikan kita. Bila ditinjau dari teori kepemimpinan pendidikan, salah satu penyebab rendahnya mutu pendidikan adalah karena rendahnya mutu kepemimpinan kepala sekolah, karena kepala sekolah adalah orang kunci yang akan mentukan sukses atau gagalnya sekolah dalam mencapaian tujuan sekolah (Lunenber \& Orstein, 2002).

Berdasarkan data-data tersebut maka kajian ini dirancang untuk mengetahui sejauh mana pengaruh kepemimpinan kepala sekolah terhadap prestasi belajar siswa SMKN di Provinsi D.I. Yogyakarta melalui 4 tinjauan variabel bebas, yaitu: (1) "Kepemimpinan Kepala Sekolah (X1), Budaya Sekolah (X2), Iklim Organisasi 
(X3), Manajemen Mutu Guru (X4), dan

Total Quality Management (X5)". Kelima variabel bebas tersebut akan dilihat sejauhmana besar pengaruhnya terhadap Prestasi Belajar Siswa (Y) yang merupakan variabel terikat dalam kajian ini.

Kelima Variabel di atas penting untuk diteliti dikarenakan di Indonesia belum banyak pendekatan kajian pembelajaran yang didasarkan kepemimpinan kepala sekolah. Kepemimpinan kepala sekolah perlu diteliti karena: (1) merupakan komponen paling penting dalam meningkatkan mutu pembelajaran (Bush, 2008 \& Hammond, et al., 2010), (2) faktor penting yang menentukan keefektifan sekolah (Huber, 2010), (3) mengantisipasi tuntutan kompetensi kepala sekolah abad ke-21, (4) mendukung keberhasilan implementasi kurikulum, (5) kepemimpinan sekolah paling sukses jika difokuskan pada pembelajaran (Leihwood \& Riehl \& Gurr, 2008; Drysdale, 2008), dan (6) sukses atau gagalnya sekolah mencapai tujuan ditentukan oleh kepemimpinan kepala sekolahnya (Hoy \& Miskel, 2013; Bass \& Bass, 2008 \& Huber, 2010).

\section{METODE}

Jenis kajian ini termasuk penelitian kuantitatif dengan menggunakan desain penelitian korelasional. Tujuan dari penelitian ini adalah mengetahui hubungan dari satu variabel dengan variabel lain. Hubungan dinyatakan dengan besarnya koefisien korelasi dan signifikansi secara statistik. Berdasarkan koefisien korelasi tersebut dapat diketahui erat tidaknya hubungan antar variable. Pendekatan yang digunakan dalam kajian ini adalah pendekatan kuantitatif atau analisis data statistik.
Kajian ini dilakukan di SMKN di Provinsi D.I. Yogyakarta. Populasi adalah seluruh karakteristik yang dimiliki objek kajian, dalam kajian ini populasi yaitu seluruh guru SMKN di Provinsi D.I Yogyakarta berjumlah 69 guru. Sample adalah bagian dari populasi yang dianggap dapat mewakili populasi. Berdasarkan tabel yang dikembangkan oleh Isaac dan Michael, dengan populasi 69 guru dan taraf kesalahan 5\% didapat sampel sebanyak 61 guru dengan metode interpolasi.

Variabel kajian terbagi menjadi variabel bebas dan variabel terikat. Variabel bebas dalam kajian ini adalah "Kepemimpinan Kepala Sekolah ( $\left.\mathrm{X}_{1}\right)$, Budaya Sekolah $\left(\mathrm{X}_{2}\right)$, Iklim Organisasi $\left(\mathrm{X}_{3}\right)$, Manajemen Mutu Guru $\left(\mathrm{X}_{4}\right)$ dan Total Quality Managemen (X5)". Variabel terikat yang diukur adalah Hasil Belajar Peserta Didik (Y). Hubungan antar variabel kajian seperti gambar berikut:

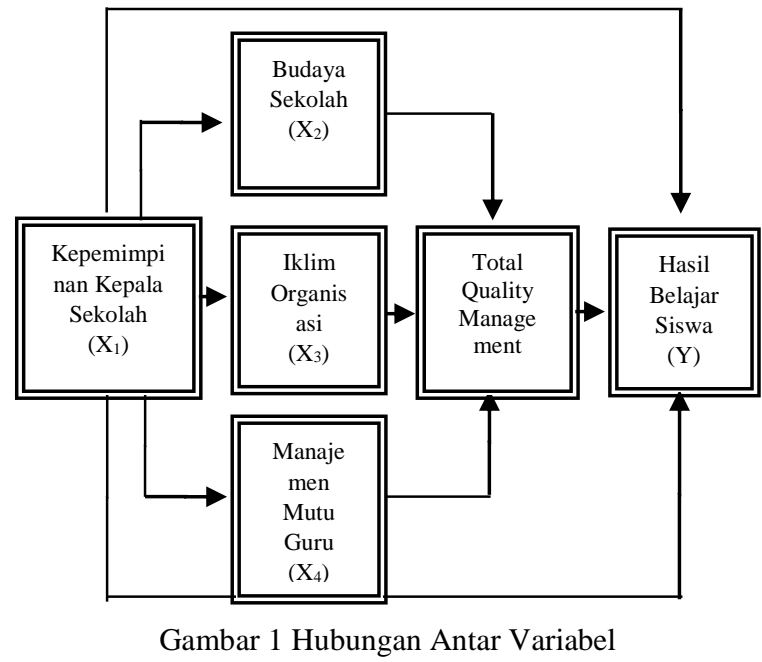

Data dalam kajian diperoleh dari kepala sekolah, wakil kepala sekolah dan guru SMKN di Provinsi D.I. Yogyakarta. Data kajian terdiri dari dua jenis data yaitu: (1) data primer yaitu data yang diperoleh langsung oleh peneliti berupa variabel $\left(\mathrm{X}_{1}\right)$ - $\left(\mathrm{X}_{5}\right)$ dan (2) data sekunder berupa variabel (Y) yaitu hasil belajar siswa. 
Teknik pengumpulan data yang digunakan yaitu: (1) metode angket merupakan kumpulan pertanyaan yang diajukan secara tertulis kepada subyek kajian atau disebut responden, 2) metode dokumentasi merupakan pengumpulan data yang telah ada di sekolah yaitu berupa data prestasi belajar siswa.

Analisis data menggunakan dua teknik yaitu statistik deskriptif kuantitatif dan yang kedua menggunakan Regresi. Kedua teknik ini akan digunakan secara bersama-sama dalam analisis data dan menjadi satu kesatuan dari keseluruhan analisis data lalu di analisis menggunakan analisis jalur (path analisys). Terdapat dua tahapan dalam menganalisis data kajian, yaitu: (1) pengolahan data dengan menggunakan rumus-rumus yang ada sesuai dengan pendekatan kajian yang diambil. Setelah data diolah dan dimasukkan ke dalam tabel, selanjutnya adalah menganalisis atau menguji data tersebut dengan analisis kuantitatif atau statistik. (2) analisis data, analisis data ini terdiri dari deskripsi data dan pengujian persyaratan analisis. Pengujian persyaratan analisis terdiri dari (a) uji normalitas, (b) uji linieritas, (c) uji validitas, (d) uji reliabilitas, (e) regresi sederhana, (f) pengujian hipotesis terdiri dari uji t (uji koefisien regresi parsial)

Uji normalitas yang digunakan peneliti adalah uji kolmogorov-smirnov satu sampel dengan SPSS. Uji linieritas dibutuhkan untuk melakukan regresi yang bertujuan untuk menguji hubungan antara variabel bebas dan variabel terikat melalui persamaan regresi linier, baik regeresi sederhana maupun regresi ganda. Hasil uji linieritas variabel bebas dengan variabel terikat dilihat dari kolom signifikansi pada baris Deviation from Linierity di tabel Anova.
Uji validitas yang dipakai adalah validitas internal. Untuk mengetahui validitas instrument pada kajian ini, digunakan program SPSS 16.0 for Windows dengan rumus sebagai berikut.

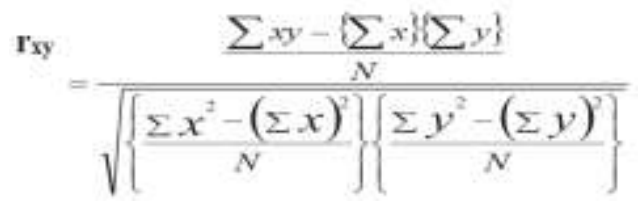

Di mana:

$\mathrm{r}_{\mathrm{xy}}$ : koefisien korelasi antara $\mathrm{x}$ dan y rxy

$\mathrm{N}$ : Jumlah Subyek

$\mathrm{X}$ : Skor item

Y : Skor total

$\Sigma \mathrm{X}$ : Jumlah skor items

$\Sigma Y$ : Jumlah skor total

$\Sigma \mathrm{X}^{2}$ : Jumlah kuadrat skor item

$\Sigma \mathrm{Y}^{2}$ : Jumlah kuadrat skor total.

Setelah diketahui nilai $\mathrm{r}_{\mathrm{xy}}\left(\mathrm{r}_{\text {hitung }}\right)$, maka nilai tersebut dibandingkan dengan $r_{\text {tabel }}$ untuk mengetahui valid tidaknya instrumen kajian, dengan taraf signifikansi $5 \%$. Apabila $r_{\text {hitung }} \geq r_{\text {tabel }}$ maka butir pertanyaan atau pernyataan valid dan jika $r_{\text {hitung }}<r_{\text {tabel }}$ maka butir pertanyaan atau pernyataan tidak valid. Analisis uji validitas butir instrumen pada kajian ini menggunakan bantuan program komputer SPSS. Nilai $\mathrm{r}_{\text {tabel }}$ didapatkan dari hasil interpolasi pada "Tabel Nilai-Nilai r Product Moment Karl Pearson" dengan jumlah responden 6 siswa dan taraf signifikan 5\% yaitu sebesar 0,252.

Uji reliabilitas yang dipakai adalah reliabilitas internal, yaitu menganalisis data dari satu kali hasil uji. Uji reliabilitas dengan menggunakan rumus sebagai berikut.

$$
\alpha=\frac{k}{k-1}\left(1-\frac{\sum S^{2} j}{S^{2} x}\right)
$$

Di mana:

$\alpha=$ koefisien reliabilitas alpha

$\mathrm{k}=$ jumlah item

$\mathrm{Sj}=$ varians responden untuk item I

$\mathrm{Sx}=$ jumlah varians skor total. 
Analisis regresi dipergunakan untuk menelaah hubungan antara dua variabel atau lebih, terutama untuk menelusuri pola hubungan yang modelnya belum diketahui dengan sempurna. Rumus yang dapat digunakan untuk mencari a dan $\mathrm{b}$ adalah sebagai berikut.

$$
\begin{aligned}
& a=\frac{\sum Y-b \sum X}{N .}=\bar{Y}-b \bar{X} \\
& b=\frac{N\left(\sum X Y\right)-\sum X \sum Y}{N \cdot \sum X^{2}-\left(\sum X\right)^{2}}
\end{aligned}
$$

Keterangan:

$\mathrm{Y}_{\mathrm{i}}=$ rata-rata skor variabel $\mathrm{X}$

$\mathrm{X}_{\mathrm{i}}=$ rata-rata skor variabel $\mathrm{Y}$

Namun demikian, untuk memudahkan analisis regresi maka peneliti menggunakan perhitungan dengan SPSS 16.0 for windows.

Tahap terakhir adalah tahap pengujian hipotesis dengan menggunakan uji t untuk menunjukkan ada tidaknya pengaruh satu variabel bebas secara individual terhadap variabel terikat. Formulasi hipotesis:

1) Ho : bi $=0$; artinya variabel bebas secara individual tidak mempunyai pengaruh yang signifikan terhadap variabel terikat.

2) $\mathrm{Ha}:$ bi $\neq 0$; artinya variabel bebas secara individual mempunyai pengaruh yang signifikan terhadap variabel terikat.

Untuk menguji kebenaran hipotesis tersebut digunakan statistik (t) yang dihitung dengan cara sebagai berikut.

$t_{\text {hitung }}=\frac{b}{s b}$

Di mana :

$\mathrm{b}=$ Koefisien regresi

$\mathrm{Sb}=$ Standar deviasi (standar error) dari koefisien $b$.

Tingkat signifikansi ditentukan dengan $\alpha=5 \%$. Untuk memudahkan peneliti dalam penghitungan statistik, digunakan bantuan program SPSS 19.0 for Windows.

\section{HASIL DAN PEMBAHASAN}

Berdasarkan analisis deskriptif data angket yang diolah dengan menggunakan bantuan SPSS versi 19.0 for window menghasilkan nilai data kepemimpinan kepala sekolah yaitu jumlah (N) adalah 61, Mean (rata-rata) adalah 71.02, Median adalah 72.00, Modus adalah 72, Standar Deviasi (SD) adalah 7.168, skor minimum 41 dan skor maksimum 81 .

Dari data tersebut dapat disusun tabel distribusi frekuensi dengan cara menentukan jumlah kelas interval $(\mathrm{k})$ yaitu 6,891 (dibulatkan menjadi 7), menghitung panjang jangkauan (range) yaitu 40, menghitung panjang interval kelas yaitu 5.7142 (dibulatkan menjadi 6). Berdasarkan hasil perhitungan maka dapat dibuat tabel distribusi frekuensi kepemimpinan kepala sekolah yaitu sebagai berikut:

Tabel 2. Distribusi Frekuensi Kepemimpinan Kepala Sekolah

\begin{tabular}{cccc}
\hline No & Interval Skor & Frekuensi & Mean \\
\hline 1 & $41-46$ & 2 & 71.02 \\
\hline 2 & $47-52$ & 2 & 71.02 \\
\hline 3 & $53-58$ & 2 & 71.02 \\
\hline 4 & $59-64$ & 12 & 71.02 \\
\hline 5 & $65-70$ & 21 & 71.02 \\
\hline 6 & $71-76$ & 14 & 71.02 \\
\hline 7 & $77-82$ & 8 & 71.02 \\
\hline & TOTAL & 61 & \\
\hline
\end{tabular}

Sumber: Data Primer yang Diolah

Berdasarkan nilai rata-rata (mean), data dapat dikategorikan menjadi dua bagian yaitu data dengan skor dibawah nilai ratarata dan data dengan skor di atas nilai ratarata yaitu skor $<71.02$ (rata-rata) sebanyak 39 orang dan Skor $>71.02$ (rata-rata) sebanyak 22 orang.

Berdasarkan analisis deskriptif menghasilkan Nilai Data Budaya Sekolah yaitu jumlah $(\mathrm{N})$ adalah 61, Mean (ratarata) adalah 109.84, Median adalah 110.00, Modus adalah 108, Standar Deviasi (SD) 
adalah 10.684, skor minimum 70 dan skor maksimum 133.

Dari data tersebut dapat disusun tabel distribusi frekuensi dengan cara menentukan jumlah kelas interval $(\mathrm{k})$ yaitu 6,891 (dibulatkan menjadi 7), menghitung panjang jangkauan (range) yaitu 63, menghitung panjang interval kelas yaitu 9 . Berdasarkan hasil perhitungan maka dapat dibuat tabel sebagai berikut:

Tabel 3. Distribusi Frekuensi Budaya Sekolah

\begin{tabular}{|c|c|c|c|}
\hline No & Interval Skor & Frekuensi & Mean \\
\hline 1 & $70-78$ & 2 & 109.84 \\
\hline 2 & $79-87$ & 1 & 109.84 \\
\hline 3 & $88-96$ & 4 & 109.84 \\
\hline 4 & $97-105$ & 7 & 109.84 \\
\hline 5 & $106-114$ & 30 & 109.84 \\
\hline 6 & $115-123$ & 13 & 109.84 \\
\hline \multirow[t]{2}{*}{7} & $124-133$ & 4 & 109.84 \\
\hline & TOTAL & 61 & \\
\hline
\end{tabular}

Sumber: Data Primer yang Diolah

Berdasarkan nilai rata-rata (mean), data dapat dikategorikan menjadi dua bagian yaitu data dengan skor dibawah nilai ratarata dan data dengan skor di atas nilai ratarata. Skor $<109.84$ (rata-rata) sebanyak 26 orang dan Skor>109.84 (rata-rata) sebanyak 35 orang.

Berdasarkan analisis deskriptif menghasilkan nilai data iklim organisasi yaitu umlah $(\mathrm{N})$ adalah 61, Mean (rata-rata) adalah 73.73, Median adalah 73.00, Modus adalah 72, Standar Deviasi (SD) adalah 7.847, skor minimum 45 dan skor maksimum 93.

Dari data tersebut dapat disusun tabel distribusi frekuensi dengan cara menentukan jumlah kelas interval $(\mathrm{k})$ yaitu 6,891 (dibulatkan menjadi 7), menghitung panjang jangkauan (range) yaitu 48, menghitung panjang interval kelas yaitu 5.71426 .857 (dibulatkan menjadi= 7) Berdasarkan hasil perhitungan maka dapat dibuat tabel distribusi frekuensi iklim organisasi yaitu sebagai berikut:

Tabel 4. Distribusi Frekuensi Iklim Organisasi

\begin{tabular}{cccc}
\hline No & Interval Skor & Frekuensi & Mean \\
\hline 1 & $45-51$ & 1 & 73.73 \\
\hline 2 & $52-58$ & 2 & 73.73 \\
\hline 3 & $59-65$ & 2 & 73.73 \\
\hline 4 & $66-72$ & 24 & 73.73 \\
\hline 5 & $73-79$ & 22 & 73.73 \\
\hline 6 & $80-86$ & 8 & 73.73 \\
\hline 7 & $87-93$ & 2 & 73.73 \\
\hline & TOTAL & 61 & \\
\hline
\end{tabular}

Sumber: Data Primer yang Diolah

Berdasarkan nilai rata-rata (mean), data dapat dikategorikan menjadi dua bagian yaitu data dengan skor dibawah nilai ratarata dan data dengan skor di atas nilai ratarata yaitu Skor<73.73 (rata-rata) sebanyak 30 dan Skor>73.73 (rata-rata) sebanyak 31.

Berdasarkan analisis deskriptif menghasilkan nilai data Manajemen Mutu Guru yaitu jumlah (N) adalah 61, Mean (rata-rata) adalah 97.92, Median adalah 97.00, Modus adalah 96, Standar Deviasi (SD) adalah 8.849, skor minimum 66 dan skor maksimum 125.

Dari data tersebut dapat menentukan jumlah kelas interval (k) yaitu 6,891 (dibulatkan menjadi 7), menghitung panjang jangkauan (range) yaitu 59, menghitung panjang interval kelas yaitu 8.428 (dibulatkan menjadi =9) Berdasarkan hasil perhitungan di atas, maka dapat dibuat tabel distribusi frekuensi manajemen mutu guru yaitu sebagai berikut.

Tabel 5. Distribusi Frekuensi Manajemen Mutu Guru

\begin{tabular}{cccc}
\hline No & Interval Skor & Frekuensi & Mean \\
\hline 1 & $66-74$ & 2 & 97.92 \\
\hline 2 & $75-83$ & 2 & 97.92 \\
\hline 3 & $84-92$ & 3 & 97.92 \\
\hline 4 & $93-101$ & 34 & 97.92 \\
\hline 5 & $102-110$ & 18 & 97.92 \\
\hline 6 & $111-119$ & 1 & 97.92 \\
\hline 7 & $120-128$ & 1 & 97.92 \\
\hline & TOTAL & 61 & \\
\hline
\end{tabular}


Sumber: Data Primer yang Diolah

Berdasarkan nilai rata-rata (mean), data dapat dikategorikan menjadi dua bagian yaitu data dengan skor dibawah nilai ratarata dan data dengan skor di atas nilai ratarata yaitu Skor<97.92 (rata-rata) sebanyak 25 dan Skor>97.92 (rata-rata) sebanyak 36.

Berdasarkan analisis deskriptif menghasilkan nilai data yaitu jumlah $(\mathrm{N})$ adalah 2, Mean (rata-rata) adalah 95.00, Median adalah 95.00, Modus adalah 94, Standar Deviasi (SD) adalah 1.414, skor minimum 94 dan skor maksimum 96.

Dari data tersebut dapat disusun tabel distribusi frekuensi dengan cara menentukan jumlah kelas interval (k) yaitu 1.993 (dibulatkan menjadi 2), menghitung panjang jangkauan (range) yaitu 2, menghitung panjang interval kelas yaitu 1 . Berdasarkan hasil perhitungan di atas, maka dapat dibuat tabel distribusi frekuensi total quality managemen yaitu sebagai berikut.

Tabel 6. Distribusi Frekuensi Total Quality Management

\begin{tabular}{cccc}
\hline No & Interval Skor & Frekuensi & Mean \\
\hline 1 & $94-95$ & 1 & 95.00 \\
\hline 2 & $96-97$ & 1 & 95.00 \\
\hline \multicolumn{2}{c}{ Total } & 2 & \\
\hline
\end{tabular}

Berdasarkan nilai rata-rata (mean), data dapat dikategorikan menjadi dua bagian yaitu data dengan skor dibawah nilai ratarata dan data dengan skor di atas nilai ratarata yaitu Skor $<95.00$ (rata-rata) yaitu 1 dan Skor $>95.00$ (rata-rata) yaitu 1 .

Berdasarkan data kajian yang diperoleh dari nilai rapor mata pelajaran kejuruan, nilai tertinggi adalah 85 dan nilai terendah 65 Hasil pengolahan dengan menggunakan bantuan program SPSS menunjukkan data yaitu jumlah (N) adalah 76, Mean (ratarata) adalah 79.41, Median adalah 79.75,
Modus adalah 78, Standar Deviasi (SD) adalah 3.464, skor minimum 62 dan skor maksimum 85. Berdasarkan hasil data di atas dapat dibuat tabel distribusi frekuensi hasil belajar siswa yaitu sebagai berikut.

Tabel 7. Distribusi Frekuensi Hasil Belajar Siswa

\begin{tabular}{cccc}
\hline No & Interval Skor & Frekuensi & Mean \\
\hline 1 & 62 & 1 & 79.41 \\
2 & 70 & 1 & 79.41 \\
3 & 73 & 1 & 79.41 \\
4 & 74 & 1 & 79.41 \\
5 & 75 & 3 & 79.41 \\
6 & 76 & 1 & 79.41 \\
7 & 77 & 5 & 79.41 \\
8 & 78 & 11 & 79.41 \\
9 & 79 & 7 & 79.41 \\
10 & 80 & 15 & 79.41 \\
11 & 81 & 10 & 79.41 \\
12 & 82 & 10 & 79.41 \\
13 & 83 & 4 & 79.41 \\
14 & 84 & 5 & 79.41 \\
15 & 85 & 1 & 79.41 \\
& TOTAL & 76 & \\
\hline
\end{tabular}

Sumber: Data Primer yang Diolah

Data variabel diatas dapat dikategorikan menjadi 10 kelompok berdasarkan keterangan nilai rapor dengan angka sebagai berikut.

Tabel 8. Kategori Keterangan Nilai Rapor dengan Angka

\begin{tabular}{cccc}
\hline No & Angka & Keterangan & Frekuensi \\
\hline 1 & 100 & Istimewa & 0 \\
2 & 90 & Baik Sekali & 0 \\
3 & 80 & Baik & 45 \\
4 & 70 & Lebih dari Cukup & 30 \\
5 & 60 & Cukup & 1 \\
6 & 50 & Hampir Cukup & 0 \\
7 & 40 & Kurang & 0 \\
8 & 30 & Kurang Sekali & 0 \\
9 & 20 & Buruk & 0 \\
10 & 10 & Buruk Sekali & 0 \\
\hline
\end{tabular}

Sumber: Data Primer yang Diolah

Berdasarkan data pada table, nilai ratarata rapor mata pelajaran kejuruan semester 5 siswa kelas XII dari kelas Teknik Bangunan, Teknik Pemesinan, dan Teknik Listrik SMKN di Provinsi D.I. Yogyakarta 
pada kategori baik sebanyak 45, lebih dari cukup 30 dan cukup sebanyak 1 .

Uji normalitas bertujuan untuk menguji apakah nilai residual berdistribusi normal atau tidak. Nilai residual dikatakan normal jika nilai signifikansinya lebih besar dari 0,05 dan data dikatakan tidak normal jika nilai signifikansinya lebih kecil dari 0,05. Pengolahan data dengan menggunakan SPSS, diperoleh nilai residual dengan signifikansi sebesar 0.723 . Nilai residual terserbut berdistribusi normal karena nilai signifikansinya $>0,05$.

Uji linieritas bertujuan untuk menguji apakah hubungan antara dua buah variabel (variabel bebas dengan variabel terikat) memiliki hubungan yang bersifat linier atau tidak linier. Apabila nilai signifikansi $>0,05$ maka bersifat linier, jika nilai signifikansi $<0,05$ maka bersifat tidak linier.

Apabila berdasarkan nilai F, maka $F_{\text {hitung }}$ dibandingkan dengan harga $F_{\text {tabel }}$ dengan taraf signifikansi 5\%. Jika $\mathrm{F}_{\text {hitung }}<$ $\mathrm{F}_{\text {tabel }}$ maka hubungan variabel $\mathrm{X}$ dengan $\mathrm{Y}$ bersifat linier dan sebaliknya jika $F_{\text {hitung }}>$ $F_{\text {tabel }}$ maka bersifat tidak linier (Triyono, 2013).

Tabel 9. Hasil Uji Linieritas

\begin{tabular}{ccccc}
\hline No & Variabel & Sig. & alpha & Ket \\
\hline 1 & X1 dengan Y & 0.076 & 0.05 & Linier \\
2 & X2 dengan Y & 0.842 & 0.05 & Linier \\
3 & X3 dengan Y & 0.248 & 0.05 & Linier \\
4 & X4 dengan Y & $0 . .212$ & 0.05 & Linier \\
5 & X5 dengan Y & 0.120 & 0.05 & Linier \\
\hline \multicolumn{5}{l}{ Sumber: Data Primer yang Diolah } \\
\end{tabular}

Berdasarkan tabel hasil uji linieritas di atas dapat diambil kesimpulan bahwa semua variable kajian dapat dikatakan linier, karena telah memenuhi kriteria pengujian linieritas yang terlihat dari kolom signifikansi pada baris Deviation from Liniearity di tabel Anova.
Uji multikolinieritas dilakukan dengan menggunakan bantuan program SPSS. Multikolinieritas dapat dideteksi dengan melihat nilai VIF (Variance Inflation Facto) dan besaran korelasi antar variabel bebas. Apabila nilai $\mathrm{VIF}<10$, nilai tolerance $>0,1$ dan koefisien korelasi antar variabel $\leq 0,60$ dapat disimpulkan antar variabel bebas tidak terjadi multikolinieritas (Danang Sunyoto, 2007). Berikut hasil uji multikolinieritas yang telah dilakukan.

Tabel 10. Hasil Uji Multikolinieritas

\begin{tabular}{|c|c|c|c|c|}
\hline No & Var & VIF & $\begin{array}{l}\text { Tole- } \\
\text { ransi }\end{array}$ & Kesimpulan \\
\hline 1 & $\mathrm{X} 1$ & $\begin{array}{c}1.52 \\
0\end{array}$ & 0.658 & $\begin{array}{c}\text { Tidak Terjadi } \\
\text { Multikolinieritas }\end{array}$ \\
\hline 2 & $\mathrm{X} 2$ & $\begin{array}{c}1.93 \\
2\end{array}$ & 0.518 & $\begin{array}{l}\text { Tidak Terjadi } \\
\text { Multikolinieritas }\end{array}$ \\
\hline 3 & X3 & $\begin{array}{c}1.70 \\
8\end{array}$ & 0.585 & $\begin{array}{l}\text { Tidak Terjadi } \\
\text { Multikolinieritas }\end{array}$ \\
\hline 4 & $\mathrm{X} 4$ & $\begin{array}{c}2.31 \\
0\end{array}$ & 0.433 & $\begin{array}{c}\text { Tidak Terjadi } \\
\text { Multikolinieritas }\end{array}$ \\
\hline 5 & $\mathrm{X} 5$ & $\begin{array}{c}2.17 \\
7\end{array}$ & 0.459 & $\begin{array}{c}\text { Tidak Terjadi } \\
\text { Multikolinieritas }\end{array}$ \\
\hline
\end{tabular}

Sumber: Data Primer yang Diolah

Berdasarkan tabel hasil uji multikolinier di atas dapat disimpulkan bahwa antar variabel bebas tidak terjadi multikolinieritas, karena nilai Toleransi kelima variabel lebih dari 0.1 dan VIF kurang dari 10, sehingga tidak terjadi multikolinieritas.

Pengujian hipotesis satu bertujuan untuk menginvestigasi Kepemimpinan Kepela Sekolah $\left(\mathrm{X}_{1}\right)$ terhadap Hasil Belajar Siswa (Y). Berdasarkan analisis regresi linier sederhana diperoleh nilai $\mathrm{t}$ hitung $>\mathrm{t}$ tabel $(0.366>0.2521)$ pada taraf signifikansi $5 \%$ dan nilai probabilitas sebesar 0,05. Hasil tersebut menunjukkan bahwa $\mathrm{Ha}$ diterima dan Ho ditolak, sehingga kepemimpinan kepala sekolah memiliki pengaruh yang signifikan terhadap hasil belajar siswa di SMKN di Provinsi D.I. Yogyakarta 
Pengujian hipotesis kedua bertujuan untuk menginvestigasi pengaruh kepemimpinan kepala sekolah $\left(\mathrm{X}_{1}\right)$ terhadap budaya sekolah $\left(\mathrm{X}_{2}\right)$. Berdasarkan analisis regresi linier sederhana diperoleh nilai $\mathrm{t}$ hitung $>\mathrm{t}$ tabel $(0.527>0.252)$ pada taraf signifikansi $5 \%$ dan nilai probabilitas sebesar 0,05. Hasil tersebut menunjukkan bahwa Ha diterima dan Ho ditolak, sehingga kepemimpinan kepala sekolah memiliki pengaruh yang signifikan terhadap budaya sekolah di SMKN di Provinsi D.I. Yogyakarta.

Pengujian hipotesis tiga bertujuan untuk menginvestigasi pengaruh kepemimpinan kepala sekolah $\left(\mathrm{X}_{1}\right)$ terhadap Iklim organisasi $\left(\mathrm{X}_{3}\right)$. Berdasarkan analisis regresi linier sederhana diperoleh nilai $\mathrm{t}$ hitung $>\mathrm{t}$ tabel $(0.260>0.252)$ pada taraf signifikansi $5 \%$ dan nilai probabilitas sebesar 0,05. Hasil tersebut menunjukkan bahwa Ha diterima dan Ho ditolak, sehingga kepemimpinan kepala sekolah memiliki pengaruh yang signifikan terhadap Iklim organisasi di SMKN di Provinsi D.I. Yogyakarta.

Pengujian hipotesis empat bertujuan untuk menginvestigasi pengaruh kepemimpinan kepala sekolah $\left(\mathrm{X}_{1}\right)$ terhadap Manajemen Mutu Guru $\left(\mathrm{X}_{4}\right)$. Berdasarkan analisis regresi linier sederhana diperoleh nilai $\mathrm{t}$ hitung $>\mathrm{t}$ tabel $(0.471>0.252)$ pada taraf signifikansi $5 \%$ dan nilai probabilitas sebesar 0,05. Hasil tersebut menunjukkan bahwa Ha diterima dan Ho ditolak, sehingga kepemimpinan kepala sekolah memiliki pengaruh yang signifikan terhadap Manajemen Mutu Guru di SMKN di Provinsi D.I. Yogyakarta.

Pengujian hipotesis kelima bertujuan untuk menginvestigasi pengaruh budaya sekolah $\left(\mathrm{X}_{2}\right)$, Iklim organisasi $\left(\mathrm{X}_{3}\right)$, manajemen mutu guru $\left(\mathrm{X}_{4}\right)$ terhadap Total Quality Management $\left(\mathrm{X}_{5}\right)$.

Tabel 11. Hasil Analisis Regresi Ganda Hipotesis Kelima

\begin{tabular}{lccccc}
\hline \multicolumn{6}{c}{ ANOVA $^{\text {a }}$} \\
\hline Model & $\begin{array}{c}\text { Sum of } \\
\text { Squares }\end{array}$ & Df & $\begin{array}{c}\text { Mean } \\
\text { Square }\end{array}$ & F & Sig. \\
\hline Regression & 910.725 & 3 & 303.575 & 20.890 & $.000^{\mathrm{b}}$ \\
\hline Residual & 828.324 & 57 & 14.532 & & \\
\hline Total & 1739.049 & 60 & & \\
\hline a. Dependent Variabel: Total Quality Management \\
\hline b. Predictors: (Constant), Manajemen Mutu Guru, Iklim \\
Organisasional, Budaya Sekolah \\
Sumber: Data Primer yang Diolah
\end{tabular}

Uji $\mathrm{F}$ diperoleh nilai $\mathrm{F}_{\text {hitung }}>$ dari $\mathrm{F}_{\text {table }}$ $(20.890>4.003)$ pada taraf signifikansi $5 \%$ dan nilai probabilitas 0,05 , df 1 (jumlah variabel-1) = 1, dan df $2(\mathrm{n}-\mathrm{k}-1)=59$. Budaya sekolah, Iklim organisasi dan manajemen mutu guru memiliki pengaruh yang signifikan terhadap Total Quality Management di SMKN di Provinsi D.I. Yogyakarta.

Uji hipotesis keenam bertujuan untuk menginvestigasi pengaruh Total Quality Management $\left(\mathrm{X}_{5}\right)$ terhadap Hasil Belajar Siswa (Y).

Tabel 12. Hasil Analisis Regresi Ganda Hipotesis Keenam

\begin{tabular}{llllll}
\hline \multicolumn{5}{c}{ ANOVA $^{\text {a }}$} \\
\hline Model & $\begin{array}{c}\text { Sum of } \\
\text { Squares }\end{array}$ & df & $\begin{array}{c}\text { Mean } \\
\text { Square }\end{array}$ & F & Sig. \\
\hline $\begin{array}{l}\text { Regressi } \\
\text { on }\end{array}$ & 291.236 & 1 & 291.236 & 41.712 & $.000^{\mathrm{b}}$ \\
$1 \mathrm{Residual}$ & 411.944 & 59 & 6.982 & \\
\hline Total & 703.180 & 60 & & \\
\hline a. Dependent Variabel: Hasil Belajar Siswa & \\
\hline b. Predictors: (Constant), Total Quality \\
Management \\
Sumber: Data Primer yang Diolah
\end{tabular}

Dari analisis regresi ganda hasil diperoleh untuk $\mathrm{F}$ tabel sebesar 4,003 dengan nilai signifikansi sebesar 0,000. Sehingga nilai $F_{\text {hitung }}>$ dari $F_{\text {table }}$ $(41,712>4.003)$ atau nilai $\mathrm{p}<\alpha(0,000<$ 
Pengaruh Kepemimpinan Kepala... (Indah/ hal. 1-12)

0,05), maka Ho ditolak, artinya secara bersama-sama variabel independen berpengaruh signifikan terhadap Hasil Belajar Siswa.

Uji hipotesis ketujuh bertujuan untuk menginvestigasi pengaruh Kepemimpinan kepala sekolah $\left(\mathrm{X}_{1}\right)$ terhadap Hasil Belajar Siswa (Y) melalui budaya sekolah dan total quality management.

Tabel 13. Hasil Analisis Regresi Ganda Hipotesis Ketujuh

\begin{tabular}{lccccc}
\hline \multicolumn{6}{c}{ ANOVA $^{\mathbf{a}}$} \\
\hline Model & $\begin{array}{l}\text { Sum of } \\
\text { Squares }\end{array}$ & df & $\begin{array}{l}\text { Mean } \\
\text { Square }\end{array}$ & F & Sig. \\
\hline Regression & 301.984 & 3 & 100.661 & 14.301 & $.000^{\mathrm{b}}$ \\
\hline 1 Residual & 401.196 & 57 & 7.039 & & \\
\hline Total & 703.180 & 60 & & & \\
\hline
\end{tabular}

a. Dependent Variabel: Hasil Belajar Siswa

b. Predictors: (Constant), Total Quality Management Sumber: Data Primer yang Diolah

Dari hasil analisis regresi ganda diperoleh nilai $\mathrm{F}$ dan dilakukan Uji $\mathrm{F}$ dengan menggunakan keyakinan $95 \%$, df 1 (jumlah variabel-1) $=1$, dan df $2(n-k-1)=$ 59, hasil diperoleh untuk $\mathrm{F}$ tabel sebesar 4,003 dengan nilai signifikansi sebesar 0,000. Sehingga nilai $F_{\text {hitung }}>$ dari $F_{\text {table }}$ $(14.301>4.003)$ atau nilai $\mathrm{p}<\alpha(0,000<$ $0,05)$, maka Ho ditolak, artinya variabel kepemimpinan kepala sekolah berpengaruh signifikan terhadap Hasil Belajar Siswa, dengan melalui budaya sekolah dan total quality management.

Uji hipotesis kedelapan bertujuan untuk menginvestigasi pengaruh Kepemimpinan kepala sekolah $\left(\mathrm{X}_{1}\right)$ terhadap Hasil Belajar Siswa (Y) melalui iklim organisasi dan total quality management.

Tabel 14. Hasil Analisis Regresi Ganda Hipotesis Kedelapan

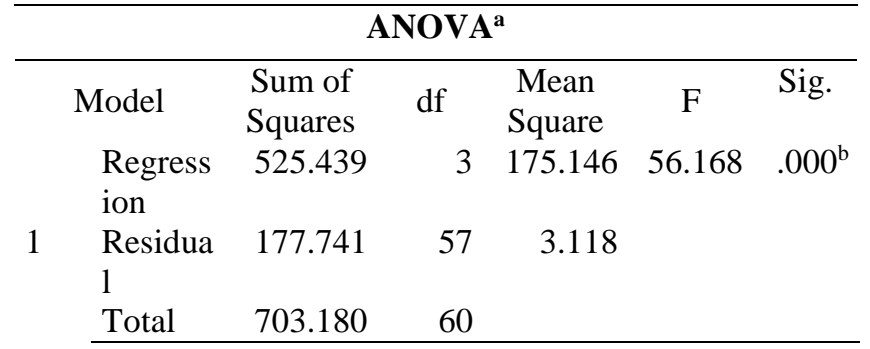

a. Dependent Variabel: Hasil Belajar Siswa

b. Predictors: (Constant), Total Quality Management Sumber: Data Primer yang Diolah

Dari hasil analisis regresi ganda diperoleh nilai $F$ dan dilakukan Uji $F$. Sehingga nilai $F_{\text {hitung }}>F_{\text {table }}(56.168>4.003)$ atau nilai $\mathrm{p}<\alpha(0,000<0,05)$, maka Ho ditolak, artinya variabel kepemimpinan kepala sekolah berpengaruh signifikan terhadap Hasil Belajar Siswa, dengan melalui budaya sekolah dan total quality management.

Hipotesis kesembilan bertujuan untuk menginvestigasi pengaruh Kepemimpinan kepala sekolah $\left(\mathrm{X}_{1}\right)$ terhadap Hasil Belajar Siswa (Y) melalui manajemen mutu guru dan total quality management.

Tabel 15. Hasil Analisis Regresi Ganda Hipotesis Ketujuh

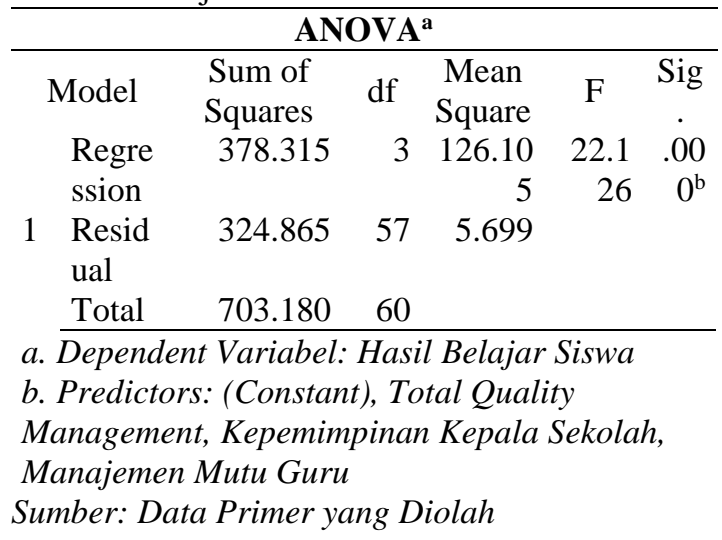

Berdasarkan hasil uji hipotesis menunjukkan bahwa Kepemimpinan Kepala Sekolah terdapat pengaruh yang signifikan terhadap hasil belajar siswa di SMKN di Provinsi D.I. Yogyakarta, dengan melalui Iklim Organisasi dan Total Quality Management. 
Hasil kajian menunjukkan bahwa Kepemimpinan Kepala Sekolah di SMKN di Provinsi D.I. Yogyakarta masuk dalam kategori baik. Hasil analisis menunjukkan nilai rata-rata yang dibagi menjadi dua kategori yaitu skor di atas nilai rata-rata (71.02) sebanyak 22 dan dibawah rata-rata (71.02) sebanyak 39. Hal tersebut menunjukkan bahwa hasil belajar siswa sangat dipengaruhi oleh kepemimpinan Kepala sekolah.

Hasil analisis data pada variabel Budaya Sekolah berdasarkan nilai mean data dibagi menjadi dua kategori yaitu data dengan skor di bawah nilai rata-rata (109.84) yaitu sebanyak 26 dan skor di atas nilai rata-rata (109.84) yaitu sebanyak 35. Hal tersebut menunjukkan bahwa hasil belajar siswa sangat dipengaruhi oleh budaya sekolah.

Hasil analisis data pada variabel ikilm organisasi berdasarkan mean data dibagi menjadi dua kategori yaitu data dengan skor di bawah nilai rata-rata (73.73) yaitu sebanyak 30 dan skor di atas nilai rata-rata (73.73) yaitu sebanyak 31. Hal tersebut menunjukkan bahwa hasil belajar siswa sangat dipengaruhi oleh ikilm organisasi.

Hasil analisis data pada variabel Manajemen Mutu Guru berdasarkan nilai mean data dibagi menjadi dua kategori yaitu data dengan skor di bawah nilai ratarata (97.92) yaitu sebanyak 25 dan skor di atas nilai rata-rata (97.92) yaitu sebanyak 36. Hal tersebut menunjukkan bahwa hasil belajar siswa sangat dipengaruhi oleh Manajemen Mutu Guru.

Berdasarkan dokumentasi nilai rapor semester 5 tahun ajaran 2017/2018 diperoleh nilai rata-rata mata pelajaran kejuruan 72 siswa kompetensi keahlian Teknik Gambar Bangunan, Teknik Listrik, dan Teknik Pemesinan. Nilai rata-rata (mean) dari nilai rapor tersebut adalah 79.41. Kategori keterangan nilai rapor dengan angka dibagi menjadi 10 kategori. Pada kajian ini, diperoleh 45 siswa berada pada kategori baik, 30 siswa dengan kategori lebih dari cukup, dan 1 dengan kategori cukup. Hal tersebut menunjukkan bahwa mayoritas siswa kompetensi keahlian Teknik Gambar Bangunan, Teknik Listrik, dan Teknik Pemesinan. Berhasil mencapai prestasi akademik kejuruan pada kategori baik.

\section{SIMPULAN}

Berdasarkan hasil analisis dan pembahasan kajian ini maka dapat diambil kesimpulan, sebagai berikut: Melalui 61 responden didapatkan kesimpulan bahwa Kepemimpinan kepala sekolah, budaya sekolah, iklim organisasi, manajemen mutu guru di SMKN di Provinsi D.I. Yogyakarta memiliki skor diatas rata-rata. Hasil belajar siswa termasuk dalam kategori baik (nilai $\geq 80$ ). Budaya Sekolah, Iklim Organisasi, Manajemen Mutu Guru di SMKN di Provinsi D.I. Yogyakarta secara bersama-sama memiliki pengaruh yang signifikan terhadap Total Quaity Managemen dan Total Quaity Managemen SMKN di Provinsi D.I. Yogyakarta memiliki pengaruh yang signifikan terhadap hasil belajar siswa.

\section{DAFTAR RUJUKAN}

Bass, M., \& Bass, R. (2008). The Bass Handbook of Leadership Theory, Research, \& Managerial Applications. Fourth Edition. New York: Free Press.

Bush, T. (2010). Leadership and management development in 
education. London: Sage

Publication, Ltd.

Education for All (EFA) Global Monitoring Report 2011: The hidden crisis, armed conflict and education. Paris: Unesco.

Gurr, D., \& Drysdale, L. (2008). Instructional Leadership in Three Australian Schools. Melbourne, Australia: Centre for Organisational Learning and Leadership, The University of Melbourne.

Hoy. W.K., \& Miskel, C.G. (2013). Educational administration: theory, practive, and research. 9th Edition. New York: McGraw-Hill.

Huber, G. S. (2010). School Leadership International Perspective. London: Springer.

Lunenburg, F.C., \& Orstein, A.C. (2000). Educational administration concepts and practices. Third Edition. Belmont: Wadsworth.

Undang-Undang Nomor 20 Tahun 2003 tentang Sistem Pendidikan Nasional. 